\title{
THE STRUCTURE OF MANUMYCIN
}

\section{ABSOLUTE CONFIGURATION AND CONFORMATIONAL STUDIES}

\author{
Ralf Thiericke, Michael StellwaAg and Axel ZeecK* \\ Institut für Organische Chemie, Universität Göttingen, \\ Tammannstraße 2, D-3400 Göttingen, FRG

\section{GÜNTHER SNATZKE} \\ Lehrstuhl für Strukturchemie, Ruhruniversität Bochum, \\ Postfach 102148, D-4630 Bochum, FRG \\ (Received for publication May 11, 1987)
}

\begin{abstract}
Chromic acid oxidation of manumycin (1), an antibiotic produced by Streptomyces parvulus (strain Tü 64), led to the isolation of 2-(2-methyl-4-oxo-2-pentenoylamino)-5,6epoxy-1,4-benzoquinone (3) and (-)-(R)-2-methylhexanoic acid (4). From the absolute configuration of 4 , determined by comparing its optical rotation with published data, follows the absolute configuration at the center of chirality in the diene side chain of manumycin (1) to be $\left(6^{\prime} R\right)$. Based on the direct comparison of the CD spectra of the two chromic acid oxidation products 2 and 3 with those of the antibiotic G7063-2 (5) and (-)-terreic acid (6) the stereochemistry at $\mathrm{C}-5$ and $\mathrm{C}-6$ of 1 was determined as $(5 R, 6 S)$. From the negative CD-couplet of manumycin (1) its stereochemistry at $\mathrm{C}-4$ was assigned as (4R).
\end{abstract}

The constitution of manumycin ${ }^{1,2)}$, an antibiotic produced by Streptomyces parvulus (Tü 64) ${ }^{32}$, was established by spectral data and chemical degradation ${ }^{4)}$. The configuration of the double bonds in the diene and triene moieties has been established by ${ }^{1} \mathrm{H}$ NMR experiments to be all-trans ${ }^{22}$. In addition, manumycin (1) exhibits four chirality centers, C-4, C-5 and C-6 in the cyclohexenone epoxide moiety, and $\mathrm{C}-6^{\prime}$ in the diene side chain. In this paper we describe a detailed $\mathrm{CD}$ analysis of both manumycin and its oxidation products obtained by chromic acid oxidation. For the first time the absolute configurations of all centers of chirality of a manumycin group antibiotic is reported.

\section{Chromic Acid Oxidation of Manumycin}

Chromic acid oxidation played a key role in the structure elucidation of manumycin $(\mathbf{1})^{1,2)}$. The resulting benzoquinone epoxide 2 represents nearly half of the parent molecule. In order to get detailed information about the selectivity of the chromic acid attack, serial reactions were carried out at room temperature by stirring 1 in $75 \%$ acetic acid and using different amounts of chromic trioxide. The reaction's time course was observed by TLC analysis on silica gel (detection at $254 \mathrm{~nm}$ ). First, compound 2 ( $R f$ 0.84), which had already been described ${ }^{2)}$, appeared together with unchanged manumycin. This oxidation step could be completed by higher concentrations of the oxidation agent within 3 hours to yield 2 as the main product. Increasing amounts of chromic trioxide and elongation of the reaction time delivered a second oxidation product ( $\mathrm{Rf} 0.66$ ), liberated from 2 . The experiments thereupon were optimized to isolate both compounds in a preparative scale.

The new oxidation product contained similar structural elements as $2 .{ }^{1} \mathrm{H}$ and ${ }^{13} \mathrm{C}$ NMR spectra implied the same 5,6-epoxy-1,4-benzoquinone partial structure but a change in the side chain, derived by oxidation of the C-4'/C-5' double bond of 2 . Additionally, a new carbonyl group appeared, de- 
Scheme 1.

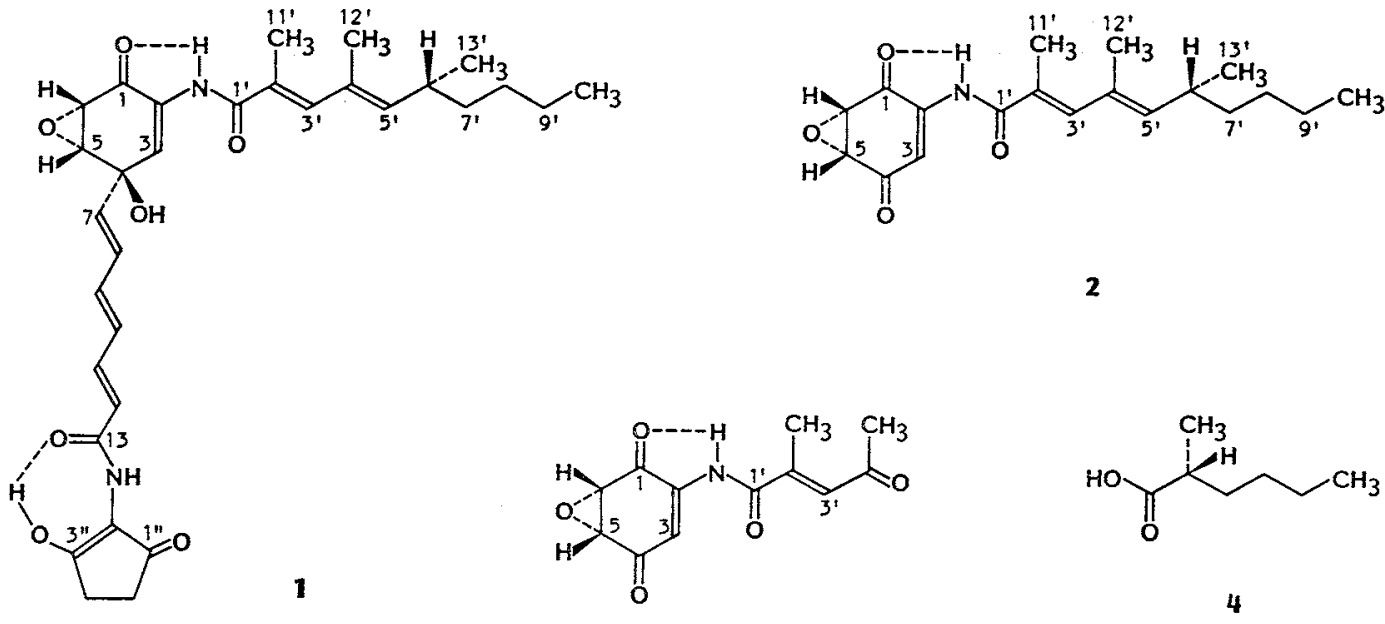

3

tectable in the IR spectrum $\left(1712 \mathrm{~cm}^{-1}\right)$ as well as in the ${ }^{13} \mathrm{C}$ NMR spectrum $\left(\delta\right.$ 198.7). The ${ }^{1} \mathrm{H}$ NMR spectrum showed signals of two methyl groups ( $\delta 2.30$ and 2.34) and one olefinic proton $(\delta 6.86)$ being relicts of the former side chain. High resolution electron impact mass spectra (EI-MS) confirmed the molecular formula $\mathrm{C}_{12} \mathrm{H}_{11} \mathrm{NO}_{5}\left(\mathrm{M}^{+} \mathrm{m} / z\right.$ 249). Thus, the structure of the new oxidation product was established as 2-(2-methyl-4-oxo-2-pentenoylamino)-5,6-epoxy-1,4-benzoquinone (3).

Simultaneously to 3 , an optically active acid, detectable on TLC by a color reaction with sodium 2,4-dichlorophenylindophenolate, could be isolated by silica gel and Sephadex LH-20 column chromatography. The molecular formula $\left(\mathrm{C}_{7} \mathrm{H}_{14} \mathrm{O}_{2}\right)$ was derived from the EI-MS $\left(\mathrm{M}^{+} m / z\right.$ 130) and a fragmentation peak ( $m / z 74)$ indicated an $\alpha$-methyl carboxylic acid. The ${ }^{1} \mathrm{H}$ NMR exhibited a carboxylic$\mathrm{OH}(\delta 11.86)$, two $C$-methyl groups ( $\delta 0.92 \mathrm{t}$ and $1.17 \mathrm{~d})$, three methylene groups $(\delta 1.38 \mathrm{br})$ and a methine proton $(\delta 2.40 \mathrm{br}$ ). These data established the structure of the acid to be 2-methylhexanoic acid (4). 3 and 4 were formed by a selective oxidative degradation of the $C-4^{\prime} / C-5^{\prime}$ double bond in 2. By this reaction, the chirality centers of 2 could be separated and recovered unchanged in 3 (C-5 and $\mathrm{C}-6)$ and $4\left(\mathrm{C}-6^{\prime}\right)$.

\section{Absolute Configuration of Manumycin}

The chirality of 4 was established by comparison of optical rotation values. Authentic $(-)-(R)$ 2 -methylhexanoic acid exhibits an optical rotation value of $[\alpha]_{D}^{20}-18^{\circ 5)}$, which was identical with the value of the acid isolated from manumycin. Thus C-6', both in 2 and in manumycin (1), has the (R)configuration.

The chromic acid oxidation resulted in the two benzoquinone-epoxides 2 and 3 , in which the chirality center at C-4 of the parent antibiotic was eliminated. The absolute configuration of 2 and 3, containing the oxirane ring, was determined by comparing their $\mathrm{CD}$ spectra with that of the antibiotic G7063-2 (5), whose absolute configuration has been previously determined ${ }^{(2)}$ by relating it to (-)-terreic acid (6) in the same way. The stereochemistry of this latter antibiotic had been proved by chemical correlation with its dihydro derivative $(-)$-terremutin $(7)^{7}$, whose stereochemistry was deduced $^{7)}$ by application of the appropriate helicity rule $^{8,9)}$ for such conjugated oxidoenones. All 
Scheme 2.<smiles>NC(=O)C1=C(N)C(=O)C2OC2C1=O</smiles>

5<smiles>CC1=C(O)C(=O)C2COCC2C1=O</smiles>

6<smiles></smiles>

7

Fig. 1. $\mathrm{CD}$ spectrum of the benzoquinone epoxides 2 (a) and 3 (b) in $\mathrm{CH}_{3} \mathrm{CN}$.

(a)

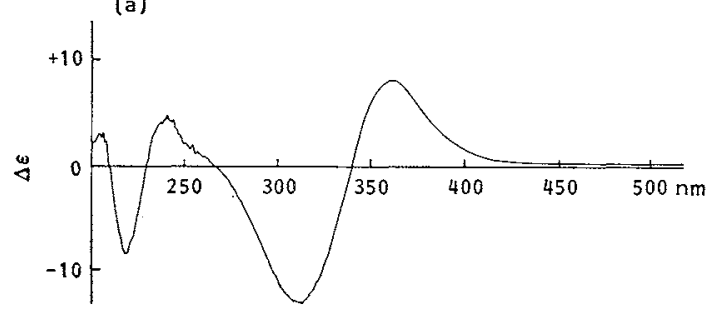

(b)

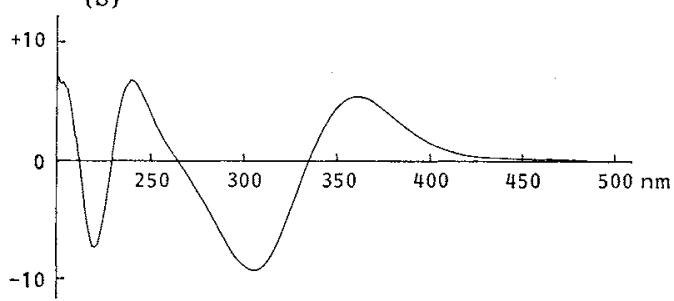

Table 1. CD values of manumycin (1), benzoquinone epoxides 2 and 3, G7063-2 (5) and (-)-terreic acid (6).

\begin{tabular}{|c|c|c|c|c|c|}
\hline \multirow{2}{*}{ Solvent } & \multicolumn{5}{|c|}{$\lambda_{\max }(\Delta \varepsilon)$} \\
\hline & 1 & 2 & 3 & 5 & 6 \\
\hline $\mathrm{CH}_{3} \mathrm{CN}$ & $\begin{array}{l}320(-13.76) \\
286(+10.23), \\
259(+3.48)\end{array}$ & $\begin{array}{l}362(+7.76), \\
312(-13.40), \\
242(+4.41), \\
218(-8.82)\end{array}$ & $\begin{array}{l}362(+5.16), \\
307(-9.68), \\
240(+6.51), \\
221(-7.78)\end{array}$ & $\begin{array}{l}376(-6.58), \\
327(+10.53), \\
233(+4.60), \\
198(-8.20)\end{array}$ & $\begin{array}{l}362(-2.00) \\
314(+2.29) \\
241(-3.33) \\
220(+4.87)\end{array}$ \\
\hline $\mathrm{CHCl}_{3}$ & $\begin{array}{l}317(-12.77), \\
284(+12.37), \\
261(+4.79)\end{array}$ & $\begin{array}{l}365(+7.57) \\
316(-12.50) \\
242(+4.57) \\
219(-8.18)\end{array}$ & $\begin{array}{l}365(+5.46) \\
311(-10.32) \\
242(+6.67) \\
223(-7.58)\end{array}$ & & \\
\hline $\mathrm{MeOH}$ & $\begin{array}{l}314(-11.87) \\
271(+13.33)\end{array}$ & $\begin{array}{l}359(+7.47), \\
308(-12.28), \\
239(+4.48), \\
219(-7.14)\end{array}$ & $\begin{array}{l}356(+4.59) \\
300(-8.61) \\
237(+5.52) \\
218(-5.30)\end{array}$ & & $\begin{array}{l}351(-1.34)^{\mathrm{a}} \\
313(+1.87)\end{array}$ \\
\hline
\end{tabular}

a Measured in $20 \%$ aq $\mathrm{MeOH}$, adjusted to $\mathrm{pH} 3^{14}$.

these compounds show two Cotton effects for $n \rightarrow \pi^{*}$ transitions between 300 and $400 \mathrm{~nm}$. These have been associated with the two individual $\mathrm{C}=\mathrm{O}$ chromophores and the difference in band position was ascribed to internal hydrogen bonding on one end of the enedione ${ }^{7}$. We have, however, ample examples of $\mathrm{CD}$ spectra of conjugated enediones at hand, and in all cases two analogous Cotton effects (of opposite or same sign) are observed, thus we rather assign these two mainly to the transitions from the symmetric and anti-symmetric combination of the energetically higher-lying n-orbitals of the two $\mathrm{C}=\mathrm{O}$ groups into $\pi^{*}{ }_{4}$, although we do not neglect some additional influence of the hydrogen bond.

The CD data observed for 2 and 3 (Fig. 1 and Table 1) are similar, showing that neither the presence of the additional center of chirality in 2 nor the difference in chain lengths has a pronounced influence on the CD. Since the two mentioned $n \rightarrow \pi^{*}$ Cotton effects of 2 and 3 have opposite signs 
Fig. 2. Two possible conformations of the cyclohexenone epoxide moiety in manumycin (1).

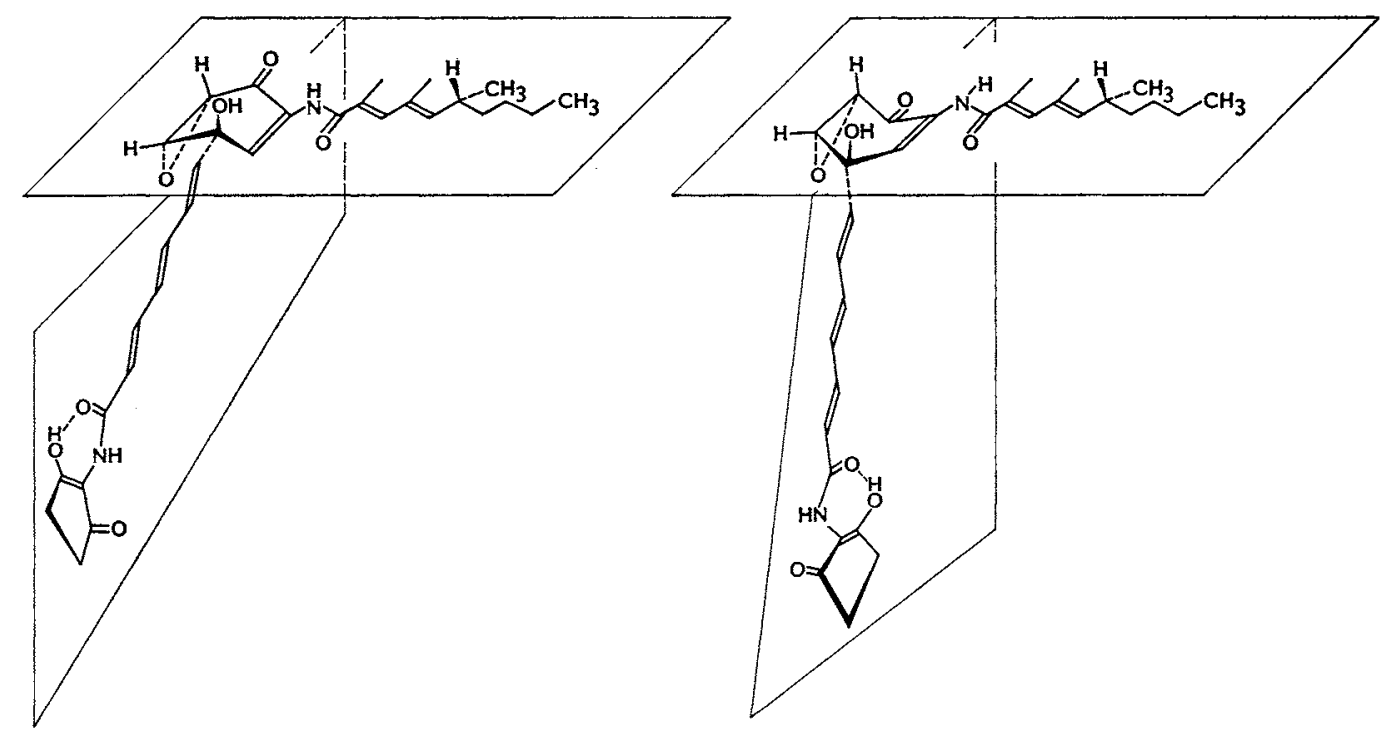

Fig. 3. $\mathrm{CD}$ spectrum of manumycin (1) in $\mathrm{CH}_{3} \mathrm{CN}$.

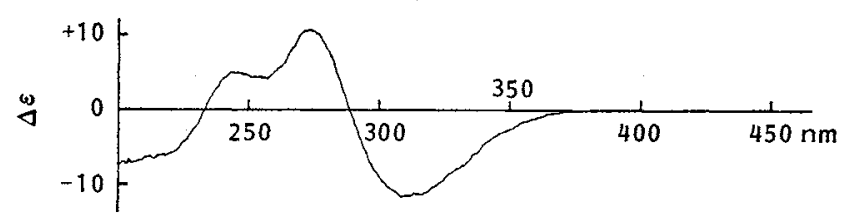

to those of 5 and 6 , they must be heterochirally analogous to the latter two, i.e. they have the $(5 R / 6 S)$ configuration. Since degradation of manumycin (1) into 2 and 3 does not affect the centers of chirality in the ring, the absolute configuration of this antibiotic at C-5 and C-6 has also been determined to be $(5 R / 6 S)$, too.

The absolute configuration at the fourth center of chirality at C-4 could be determined analogously to the way it was done for asukamycin ${ }^{10,11}$ by application of the exciton theory ${ }^{12,132}$. Prerequisites for this method are 1) the separation of two chromophores by at least one or two $\sigma$-bonds, 2) strong individual transition moments, 3) not too large difference in transition energies, and 4) a chiral arrangement of these two transition moments. Whether the $\mathrm{C}_{8}$-skeleton of the cyclohexenone ring of $\mathbf{1}$ is assumed to be planar, as discussed for asukamycin ${ }^{10)}$, or whether it is one of the conformations depicted in Fig. 2 as seems more probable to us, the sense of helicity of the combined exciton system is solely determined by the configuration at C-4. Differences in conformation will only influence the magnitude of the exciton interaction.

For 1, a medium-strong negative CD-couplet is found $\left(\Delta \varepsilon_{\max }-13.76\right.$ at $320 \mathrm{~nm},+10.23$ at 286 $\mathrm{nm}$, see Fig. 3), which is consistent only with the configuration shown in Fig. 2 proving thus the absolute configuration at $\mathrm{C}-4$ of 1 to be $(4 R)$. This is in contrast to the configuration at C-4 of asukamycin, which is $(4 S)^{102}$. The reason for the bathochromic shifts of the maxima of the CD-couplet in the spectrum of the latter compound are 1) the presence of the $Z$-configuration of two double bonds, and 2) the longer conjugation in the side chain connected to $\mathrm{C}-2$ in asukamycin. This latter fact is 
also one of the reasons for the almost three times larger values of the CD-maxima of asukamycin.

Stereochemically manumycin (1) differs thus from asukamycin at least in its configuration of the double bonds at C-7 and C-9, and at the center of chirality C-4, which leads to significant differences in the spatial structure of manumycin by location of the triene-amide chain on the other side of the cyclohexanone epoxide ring, as compared to asukamycin.

\section{Experimental}

General and Analytics

See literature citation ${ }^{2}$.

2-(2-Methyl-4-oxo-2-pentenoylamino)-5,6-epoxy-1,4-benzoquinone (3)

A solution of $2 \mathrm{~g}$ manumycin in $60 \mathrm{ml} \mathrm{90 \%} \mathrm{acetic} \mathrm{acid} \mathrm{was} \mathrm{stirred} \mathrm{for} 20$ hours at room temp with $5 \mathrm{~g} \mathrm{CrO}_{3}$ (dissolved in $60 \mathrm{ml} 60 \%$ acetic acid). The mixture was poured into $500 \mathrm{ml} 2 \mathrm{~N} \mathrm{H}_{2} \mathrm{SO}_{4}$ and then extracted with ether. The dried organic layer was evaporated and chromatographed on a silica gel column $\left(60 \times 2.5 \mathrm{~cm}, \mathrm{CHCl}_{3}-2\right.$-propanol, $\left.98: 2\right)$. The pale yellow residue was purified by Sephadex LH-20 column chromatography $\left(60 \times 2.5 \mathrm{~cm}, \mathrm{CHCl}_{3}\right)$. Two main compounds were eluted: 1) $\mathrm{Rf} 0.45\left(4, \mathrm{CHCl}_{3}-\mathrm{MeOH}, 95: 5\right.$; red spot by staining with 2,4-dichlorophenylindophenole on TLC plates); 2) Rf 0.56 (3, $\mathrm{CHCl}_{3}-\mathrm{MeOH}, 95: 5$; detection by UV light at $254 \mathrm{~nm}$ ).

3 was further purified on silica gel $\left(60 \times 2.5 \mathrm{~cm}, \mathrm{CHCl}_{3}\right.$ - 2-propanol, $\left.98: 2\right)$ to yield $37 \mathrm{mg}(4.2 \%)$ as a colorless powder: MP $140^{\circ} \mathrm{C} ;[\alpha]_{\mathrm{D}}^{22}+107^{\circ}(c 0.06, \mathrm{MeOH}) ; \mathrm{IR}(\mathrm{KBr}) \mathrm{cm}^{-1} 3360,1711,1689,1674$, 1626,1003 ; UV $\lambda_{\text {max }}^{\mathrm{NeOH}} \mathrm{nm}(\varepsilon) 309(10,800), 229(13,100) ; \lambda_{\max }^{\mathrm{MeOH}-\mathrm{HO} 1} 309(10,800), 229(13,100) ; \lambda_{\max }^{\mathrm{NeOH}-\mathrm{NaOH}}$ $345(21,300) ;{ }^{1} \mathrm{H}$ NMR $\left(100 \mathrm{MHz}, \mathrm{CDCl}_{3}\right) \delta 2.30\left(\mathrm{~d}, J=1.5 \mathrm{~Hz}, 6^{\prime}-\mathrm{H}_{3}\right), 2.34\left(\mathrm{~s}, 5^{\prime}-\mathrm{H}_{3}\right), 3.84$ (dd, $J=3$ and $2 \mathrm{~Hz}, 5-\mathrm{H}), 3.96(\mathrm{~d}, J=3 \mathrm{~Hz}, 6-\mathrm{H}), 6.86\left(\mathrm{~d}, J=1.5 \mathrm{~Hz}, 3^{\prime}-\mathrm{H}\right), 7.55$ (d, $\left.J=2 \mathrm{~Hz}, 3-\mathrm{H}\right), 8.34$ (br s, $\mathrm{NH}) ;{ }^{13} \mathrm{C} \mathrm{NMR}\left(50.3 \mathrm{MHz}, \mathrm{CDCl}_{3}\right) \delta 14.3\left(\mathrm{C}-6^{\prime}\right), 32.2\left(\mathrm{C}-5^{\prime}\right), 52.5(\mathrm{C}-5), 53.9(\mathrm{C}-6), 116.3(\mathrm{C}-3), 130.7$ (C-3'), $138.3\left(\mathrm{C}-2^{\prime}\right), 142.6$ (C-2), $166.9\left(\mathrm{C}^{\prime} \mathbf{1}^{\prime}\right), 188.0$ (C-1), 190.9 (C-4), 198.7 (C-4'); CD see Fig. 1 and Table 1; MS $(70 \mathrm{eV}) \mathrm{m} / z$ (relative intensity) $249\left(1.3 \%, \mathrm{M}^{+}\right.$, high resolution calcd for $\mathrm{C}_{12} \mathrm{H}_{11} \mathrm{NO}_{5}$ and found 249.0637), $206(2.7 \%), 179\left(11.7 \%, \mathrm{C}_{9} \mathrm{H}_{8} \mathrm{NO}_{3}, 179.0588\right), 111\left(25 \%, \mathrm{C}_{8} \mathrm{H}_{7} \mathrm{O}_{2}, 111.0445\right), 43$ $(100 \%)$.

\section{$(-)-(R)-2-$ Methylhexanoic Acid (4)}

4 was further purified by column chromatography $\left(60 \times 2.5 \mathrm{~cm}\right.$, Sephadex $\left.\mathrm{LH}-20, \mathrm{CHCl}_{3}\right)$ to yield $67.9 \mathrm{mg}(14.4 \%)$ as a colorless oil: $[\alpha]_{\mathrm{D}}^{22}-18^{\circ}\left(c 1.1, \mathrm{CHCl}_{3}\right) ;{ }^{1} \mathrm{H} \mathrm{NMR}\left(100 \mathrm{MHz}, \mathrm{CCl}_{4}\right) \delta 0.92$ $\left(\mathrm{t}, J=6 \mathrm{~Hz}, 6-\mathrm{H}_{3}\right), 1.18\left(\mathrm{~d}, J=7 \mathrm{~Hz}, 7-\mathrm{H}_{3}\right), 1.2 \sim 1.9\left(\mathrm{br} \mathrm{m}, 3-\mathrm{H}_{2}, 4-\mathrm{H}_{2}\right.$ and $\left.5-\mathrm{H}_{2}\right), 2.40(\mathrm{~m}, 2-\mathrm{H}), 11.86$ (br s, OH); MS $(70 \mathrm{eV}) \mathrm{m} / \mathrm{z}$ (relative intensity) $130\left(1 \%, \mathrm{M}^{+}\right), 115(3 \%), 101(27 \%), 87(12 \%), 74$ $(100 \%), 73(7 \%)$.

\section{Acknowledgment}

We thank the Deutsche Forschungsgemeinschaft and the Fonds der Chemischen Industrie for financial support.

\section{References}

1) SCHRöDER, K. \& A. ZEECK: Manumycin. Tetrahedron Lett. 1973: 4995 4998, 1973

2) ZeECK, A.; K. SChröder, K. Frobel, R. Grote \& R. Thiericke: The structure of manumycin. I. Characterization, structural elucidation and biological activity. J. Antibiotics 40: 1530 1540, 1987

3) Buzzetti, F.; E. Gäumann, R. HÜtter, W. Keller-Schierletn, L. Netpp, V. Prelog \& H. Zähner: Stoffwechselprodukte von Mikroorganismen, 41. Mitteilung, Manumycin. Pharm. Acta Helv. 38: 871 874,1963

4) ZeECK, A.; K. Frobel, C. Heused, K. SChröder \& R. Thiericke: The structure of manumycin. II. Derivatives. J. Antibiotics 40: $1541 \sim 1548,1987$

5) BEILSTEIN, Beilstein Institut für Literatur der Organischen Chemie, 4. Auflage, drittes Ergänzungswerk, Bd. II, 1. Teil, System Nr. 162, p. 773, Springer Verlag, Berlin, 1960 
6) Reddy, G. C. S.; R. S. Sood, S. R. Nudkarni, J. Reden, B. N. Ganguli, H. W. Fehlhaber \& G. SNatzke: Stereochemistry of the epoxydon group antibiotic G7063-2 isolated from a Streptomyces species HPL Y-25711. J. Antibiotics 37: 1596 1599, 1984

7) Mrller, M.: The structure of terremutin. Tetrahedron 24: 4839 4851, 1968

8) SNATzke, G.: Circulardichroismus IX, Modifizierung der Oktantenregel für $\alpha, \beta$-ungesättigte Ketone: Transoide Enone. Tetrahedron 21: 421 438, 1965

9) Kis, Z.; A. Closse, H. Sigg, L. Hruban \& G. Snatzke: Die Struktur von Panepoxydon und verwandten Pilzmetaboliten. Helv. Chim. Acta 53: 1577 1597, 1970

10) Kakinuma, K.; N. Ikekawa, A. Nakagawa \& S. Ōmura: The structure of asukamycin, a possible shunt metabolite from 3-dehydroquinic acid in the shikimate pathway. J. Am. Chem. Soc. 101: 3402 3404, 1979

11) HaRAda, N. \& K. NAKanishi $(E d$.$) : Circular dichroic spectroscopy, exciton coupling in organic stereo-$ chemistry. pp. $238 \sim 247$, Oxford University Press, Oxford, 1983

12) Harada, N. \& K. NaKanishi: The exciton chirality method and its application to configurational and conformational studies of natural products. Accounts Chem. Res. 5: 257 263, 1972

13) Koreeda, M.; N. Harada \& K. NaKanishi: Exciton chirality method as applied to conjugated enones, esters and lactones. J. Am. Chem. Soc. 96: 266 268, 1974

14) READ, G.: CD studies on terreic acid and its derivates. J. Chem. Soc. (London) 1965: 6587 6589, 1965 